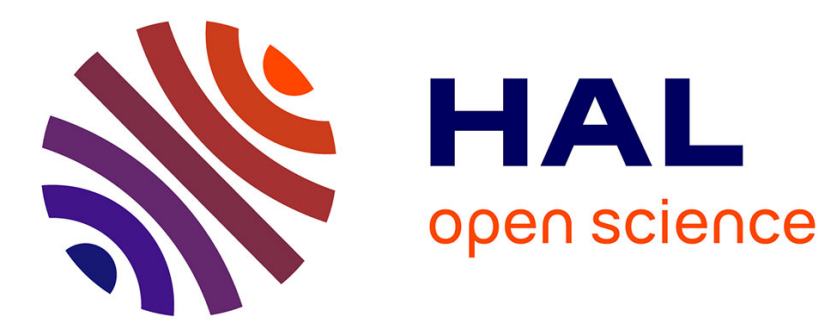

\title{
Photoacoustic measurements on Cd1-xFexTe compounds.
}

D. Debowska, A. Felici, N. Galbato, F. Lama, T. Papa, M. Piacentini

\section{To cite this version:}

D. Debowska, A. Felici, N. Galbato, F. Lama, T. Papa, et al.. Photoacoustic measurements on Cd1-xFexTe compounds.. Journal de Physique IV Proceedings, 1994, 04 (C7), pp.C7-373-C7-376. 10.1051/jp4:1994787 . jpa-00253318

\section{HAL Id: jpa-00253318 https://hal.science/jpa-00253318}

Submitted on 1 Jan 1994

HAL is a multi-disciplinary open access archive for the deposit and dissemination of scientific research documents, whether they are published or not. The documents may come from teaching and research institutions in France or abroad, or from public or private research centers.
L'archive ouverte pluridisciplinaire HAL, est destinée au dépôt et à la diffusion de documents scientifiques de niveau recherche, publiés ou non, émanant des établissements d'enseignement et de recherche français ou étrangers, des laboratoires publics ou privés. 
JOURNAL DE PHYSIQUE IV

Colloque C7, supplément au Journal de Physique III, Volume 4, juillet 1994

\title{
Photoacoustic measurements on $\mathrm{Cd}_{1-x} \mathrm{Fe}_{x} \mathrm{Te}$ compounds ${ }^{(1)}$
}

D. Debowska*, A.C. Felici, N. Galbato, F. Lama**, T. Papa and M. Piacentini

Dipartimento di Energetica, Università degli Studi di Roma "La Sapienza", Via Scarpa 14, 00161 Roma, Italy

* Institute of Physics, Jagellonian University, Reymonta 4, 30-059 Kracow, Poland

** Consorzio I.N.F.M., Via Dodecaneso 33, 16146 Genova, Italy

\begin{abstract}
We have measured at room temperature the photoacoustic spectra of $\mathrm{Cd}_{1-x} \mathrm{Fe}_{\mathrm{x}} \mathrm{Te}(0<\mathrm{x}<0.055)$ around the CdTe fundamental absorption threshold. We identified an absorption band at (1.38 \pm 0.01$) \mathrm{eV}$, increasing with the $\mathrm{Fe}$ concentration, that we assigned to the ${ }^{5} \mathrm{E} \rightarrow{ }^{3} \mathrm{~T}_{1}$ transition within the $\mathrm{Fe}^{2+}\left(3 \mathrm{~d}^{6}\right)$ manifold. We observed also a broadening and a shift to higher energies of the CdTe absorption edge for increasing $\mathrm{x}$.
\end{abstract}

The $\mathrm{Cd}_{1-\mathrm{x}} \mathrm{Fe}_{\mathrm{x}} \mathrm{Te}$ compounds belong to the large class of diluted magnetic semiconductors, ternary or quaternary compounds whose lattice is partly made up of substitutional magnetic ions. The importance of this kind of compounds is related both to their magnetic behaviour and to the possibility of tuning the energy gap, the lattice constant and other physical parameters by varying the composition. Unlike the II-VI compounds alloyed with $\mathrm{Mn}$, till now the iron based compounds haven't been studied in detail. This is mostly due to the difficulty of growing these compounds with a sufficiently high concentration.

The problem of the optical absorption of $\mathrm{Cd}_{1-x} \mathrm{Fe}_{\mathrm{x}} \mathrm{Te}$ compounds near the absorption edge is still an open question. In fact, measurements have been performed either on very diluted samples [1,2]. giving unambiguous results, or on ternary compounds $[3,4]$ with contradictory results.

In very diluted samples, iron impurities enter the CdTe crystals doubly ionised, substituting the $\mathrm{Cd}$ atoms, hence occupying a site of $\mathrm{T}_{\mathrm{d}}$ symmetry. In a crystal field of $T_{d}$ symmetry the ground state of the $\mathrm{Fe}^{2+}$ free ion, ${ }^{5} \mathrm{D}\left(3 \mathrm{~d}^{6}\right)$, splits into an orbital doublet ${ }^{5} \mathrm{E}$, which is the ground state level, and in a triplet ${ }^{5} \mathrm{~T}_{2}$, which is the first excited state. The next excited state is a ${ }^{3} T_{1}$ state [5]. The optical absorption of $\mathrm{Fe}^{2+}$ substitutional impurities in CdTe crystals, measured in the near infrared region [1,2], shows an absorption band at $0.31 \mathrm{eV}$, assigned to the ${ }^{5} \mathrm{E} \rightarrow{ }^{5} \mathrm{~T}_{2}$ transition, and a second band at about $1.38 \mathrm{eV}$, near the CdTe edge, attributed to the ${ }^{5} \mathrm{E} \rightarrow{ }^{3} \mathrm{~T}_{1}$ transition. The ionization of the ground state ${ }^{5} \mathrm{E}$ of the $\mathrm{Fe}^{2+}$ ion has been determined at $1.45 \pm 0.01 \mathrm{eV}$ from photo-EPR measurements at $5 \mathrm{~K} \mathrm{[6]} \mathrm{and} \mathrm{photoconductivity} \mathrm{measurements} \mathrm{at} 77 \mathrm{~K}$ [2]. 
When the Fe concentration is increased to obtain the $\mathrm{Cd}_{1-\mathrm{x}} \mathrm{Fe}_{\mathrm{x}} \mathrm{Te}$ ternary compounds, the $3 d$ energy levels of isolated Fe ions hybridize with the host crystal levels and with those of other Fe ions. In the high concentration limit they form energy bands, as it has been calculated for the hypothetical $\mathrm{x}=0.5$ zinc-blend mixed crystal [7]. These changes should influence the absorption coefficient spectrum near the absorption threshold of pure CdTe. The absorption coefficient spectra of $\mathrm{Cd}_{1-\mathrm{x}} \mathrm{Fe}_{\mathbf{x}} \mathrm{Te}$ mixed samples with the $\mathrm{Fe}$ concentration $\mathrm{x}$ ranging from 0.015 to 0.05 , measured in the pure CdTe threshold region [3], presented several weak structures and a shift to lower energies of the threshold. Instead the reflectivity spectra [4] presented only a structure assigned to the fundamental exciton peak, that shifts to higher energies for increasing Fe concentration, implying a shift to higher energies of the fundamental gap as well.

The aim of this work is to study in detail the behaviour of the $\mathrm{Cd}_{1-\mathrm{x}} \mathrm{Fe}_{\mathrm{x}} \mathrm{Te}$ absorption threshold as a function of the Fe concentration. We used photoacoustic spectroscopy for our investigation since it is a good technique for studying the optical properties of solid samples, especially for revealing small absorption coefficients or for studying materials that, for some reason, are not easy to prepare for conventional reflection and absorption techniques.

Figure 1 shows the experimental set-up [8], which consisted of a chopped light source, a photoacoustic cell with a microphone detector, a lock-in amplifier and a computer controlled acquisition system. The light source was a $250 \mathrm{~W}$ halogen lamp coupled with a f/4 Jobin-Yvon monochromator and was mechanically chopped at 20 $\mathrm{Hz}$. The photoacoustic cell was a stainless steel cell, closed by sapphire windows, suitably designed in order to minimise the air volume and to prevent thermo-viscous damping effects. The sample was mounted on a sapphire sample holder. The spectral energy range $1.0 \mathrm{eV}-1.8 \mathrm{eV}$, of interest for our measurements, was covered with a resolution of the order of $10 \mathrm{meV}$.

The $\mathrm{Cd}_{1-\mathrm{x}} \mathrm{Fe}_{\mathrm{x}} \mathrm{Te}$ samples were grown by means of a modified Bridgman method. The Fe content (determined by microprobe analysis with a precision better than 0.001 ) and the crystal lattice constant (determined at room temperature from X-ray diffraction using the Debye-Scherrer method) were obtained for several concentrations and a linear calibration relationship between the Fe concentration and the lattice constant was derived. The concentrations of other samples were determined indirectly measuring the lattice constant and using the calibration relationship [4,9]. The photoacustic measurements were performed on samples with $\mathrm{x}=0.00,0.001,0.035,0.055$ (direct determination) and $\mathrm{x}=0.01$ and 0.03 (indirect determination).

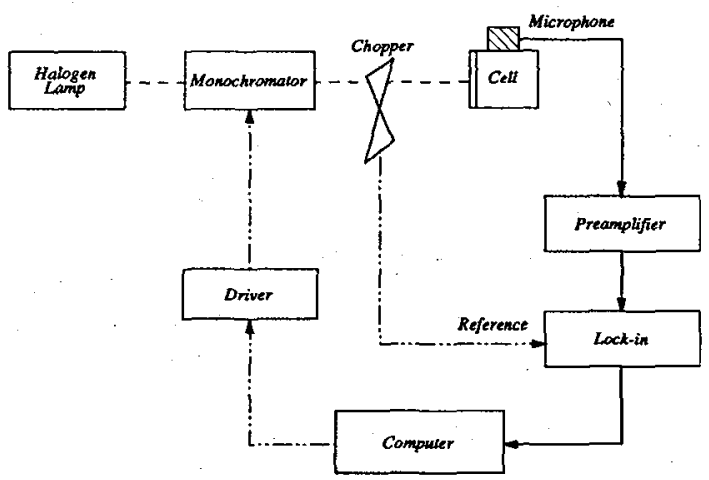

Figure 1 - Schematic diagram of the experimental set-up. 
In figure 2 we report the room temperature photoacoustic spectra of some $\mathrm{Cd}_{1-\mathrm{x}} \mathrm{Fe} \mathrm{e}_{\mathbf{x}} \mathrm{Te}$ samples $(x=0.00,0.01,0.03,0.055)$. At low energies the photoacoustic spectra of all samples show a linear - almost constant background. The spectrum of pure CdTe shows a clear and quite sharp absorption edge. The spectra of $\mathrm{Cd}_{1-\mathrm{x}} \mathrm{Fe}_{\mathrm{x}} \mathrm{Te}$ present an increasing distortion of the CdTe edge and an absorption feature below the edge, which grows with the Fe concentration. At high energies, where the light penetration depth becomes much shorter than the heat diffusion length, all the photoacustic spectra show saturation. In the region of low absorption the photoacustic signal is approximately proportional to the absorption coefficient. Within this approximation, our results agree quite well with the absorption measurements at room temperature of Slack et al. [1] on a diluted sample. We were not able to reveal the large shift to lower energies of the absorption edge and all the features present in the spectra reported in Ref. [3].

We simulated the photoacoustic spectra following the theory developed by Rosencwaig and Gersho [10] for the photoacoustic effect in solids. The simulation implies the knowledge of the density, the specific heat and the thermal conductivity of the samples. To our best knowledge the values of these quantities are not available for $\mathrm{Cd}_{1-x} \mathrm{Fe}_{\mathrm{x}} \mathrm{Te}$. We assumed that they do not change much within the small range of values of $\mathrm{Fe}$ concentration used in our measurements. We checked that the simulated photoacoustic spectra were not affected varying these parameters within reasonable limits. Thus we decided to keep them constant and we used the values of pure CdTe for all samples [1 1]. For the same reason all the spectra have been normalised to the same saturation value. The simulation requires also the knowledge of the absorption coefficient spectrum, that we have constructed adding three contributions: a linear background, a Gaussian curve for the low energy band and the threshold.

We had difficulties in examining the absorption edge line shape, since we were probing only the lowest portion of the absorption threshold. We tried several line shapes, obtaining good results. The simulations shown in Fig. 2 with the full lines were calculated assuming an "exponential step function" for the absorption coefficient $\alpha$ :

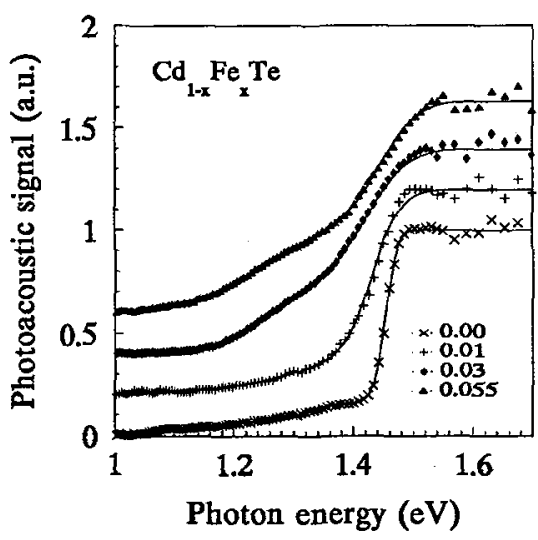

Figure 2. Photoacustic spectra of $\mathrm{Cd}_{1}$ ${ }_{\mathrm{x}} \mathrm{Fe}_{\mathrm{x}} \mathrm{Te}$ for $\mathrm{x}=0,0.1,0.3,0.55$. A constant background has been subtracted and the saturation has been normalized to unity. For the sake of clarity, the spectra have been displaced upwards by $0.2,0.4$ and 0.6 for $\mathrm{x}=0.1,0.3,0.55$ respectively. The full lines represent the photoacustic spectra obtained from the model calculation described in text.

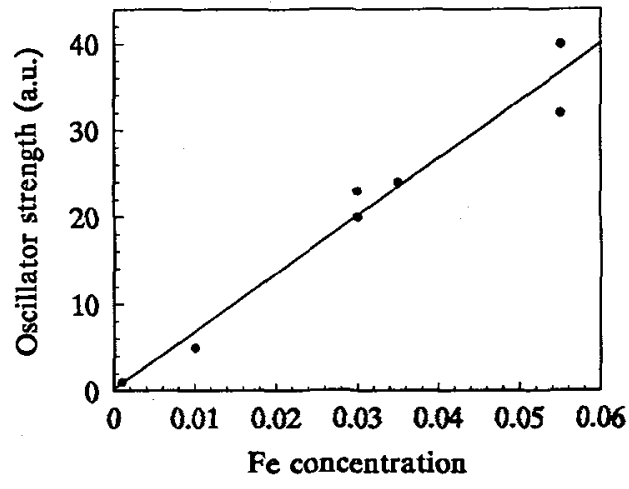

Figure 3. Oscillator strength (in arbitra., units) of the $1.38 \mathrm{eV}$ absorption band versus Fe concentration. The straight line is the best fit line passing through the experimental points. 


$$
\alpha(E)=\left\{\begin{array}{ll}
A \exp \left(\frac{E-E_{0}}{\sigma}\right) & E<E_{0} \\
A\left(2-\exp \left(\frac{E_{0}-E}{\sigma}\right)\right) & E \geq E_{0}
\end{array}\right\}
$$

where $E$ is the photon energy and $A$ is a normalization parameter. $\sigma$ is a parameter related to the curve width and increases with increasing iron concentration. Such a behaviour can be attributed to the fact that the replacement of $\mathrm{Cd}$ atoms by $\mathrm{Fe}$ ones, with a different bonding length, causes local lattice strains and distortions that reflect in an increasing broadening of the line shape. The energy $E_{0}$ can be interpreted as the absorption threshold energy and we found that it shifts to higher energies with the same slope as that determined by Debowska et al. [4] for the reflectivity exciton structure.

The low energy absorption band is well reproduced using a Gaussian curve peaked, for all the samples, at $(1.38 \pm 0.01) \mathrm{eV}$ with a half width of $(0.15 \pm 0.01) \mathrm{eV}$ and whose oscillator strength increases linearly with the Fe concentration, as shown in figure 3. This band is clearly related to transitions involving the iron ions. Alike very diluted samples, we interpret it as due to transitions within the $\mathrm{Fe}^{2+} 3 \mathrm{~d}^{6}$ manifold, in particular between the ${ }^{5} \mathrm{E}$ and the ${ }^{3} \mathrm{~T}_{1}$ states. The energy of the maximum is the same as that reported in previous optical absorption experiments $[1,2]$ and theoretical calculations [5]. In agreement with other partially ionic semiconductors [12] and with other II-VItransition metal ternary compounds [13], transitions between the transition metal 3d manifold are found in the forbidden gap, as if the excited ion behaved as an isolated impurity rather than interacting with the other transition metal ions.

In conclusion, we have measured the photoacoustic spectra of $\mathrm{Cd}_{1-\mathrm{x}} \mathrm{Fe}$. $\mathrm{Te}$ compounds confirming the presence of transitions within the $\mathrm{Fe}^{2+} 3 \mathrm{~d}$ states below the threshold. We found also an increasing broadening of the absorption edge with iron concentration that we attributed to the local disorder due to the replacement of Cd atoms with Fe ones. From the line shape analysis we also deduced a shift to higher energies of the absorption threshold.

Acknowledgments: The authors are strongly indebted to A. Kisiel, R. Markowski and N. Zema for stimulating discussions. The samples were grown by W. Giriat, Instituto Venezolano de Investigationes Cientificas, Centro de Fisica, Caracas. Financial support for the exchange visits was obtained through the Direct Research Exchange Program between the University of Rome "La Sapienza" and the Jagellonian University.

\section{References}

[1] Slack G.A., Roberts S., and Vallin J.T., Phys. Rev. 187 (1969) 511-524.

[2] Szadkowski A.J., J. Phys. C 2 (1990) 9853-9859.

[3] Joshi N.V. and Mogollon L., Prog. Cryst. Growth Char. 10 (1985) 65-70.

[4] Debowska D., Zimnal-Starnawska M., Rodzik A., Kisiel A., Piacentini M., Zema N., and Giriat W., J. Phys.: Cond. Matter (in press).

[5] Fazzio A., Caldas M.J., and Zunger A., Phys. Rev. B 30 (1984) 3430-3455.

[6] Lischka K., Brunthaler G., and Jantsch W., J. Cryst. Growth 72 (1985) 355-359.

[7] Markowski R., private communication.

[8] Galbato N., thesis.

[9] Debowska D., PhD. thesis.

[10] Ronsencwaig A. and Gersho A., J. Appl. Phys. 47 (1976) 64-76.

[1 1] Landolt - Börnstein, New Series III/17b (Springer - Verlag, Berlin, 1982) p. 459.

[12] Piacentini M., Khumalo F.S., Leveque G., Olson C.G., and Lynch D.W., Chem. Phys. 72 (1982) 61-71.

[13] Becker W.M., "Diluted Magnetic Semiconductors", Semiconductors and Semimetals, Vol. 25 (Furdyna J.K. and Kossut J. editors, Academic Press, London 1988) pp.35-72. 